\title{
Canine visceral leishmaniasis: Incidence and risk factors for infection in a cohort study in Brazil
}

\author{
Wendel Coura-Vital ${ }^{\mathrm{a}, \mathrm{b}, \mathrm{c}, \mathrm{f}, *}$, Alexandre Barbosa Reis ${ }^{\mathrm{c}, \mathrm{d}, \mathrm{f}}$, \\ Levi Eduardo Soares Reis c,d , Samuel Leôncio Bragac, d, Bruno Mendes Roatt ${ }^{c, d, f}$, \\ Rodrigo Dian de Oliveira Aguiar-Soares ${ }^{c, d, f}$, Marcos José Marques ${ }^{e}$, \\ Vanja Maria Veloso ${ }^{\mathrm{c}}$, Mariângela Carneiro ${ }^{\mathrm{a}, \mathrm{b}}$ \\ a Pós-Graduação em Ciências da Saúde: Infectologia e Medicina Tropical, Faculdade de Medicina, Universidade Federal de Minas Gerais, \\ Avenida Alfredo Balena 190, CEP 30130-100 Belo Horizonte, Minas Gerais, Brazil \\ b Laboratório de Epidemiologia de Doenças Infecciosas e Parasitárias, Departamento de Parasitologia, Instituto de Ciências Biológicas, \\ Universidade Federal de Minas Gerais, Campus Pampulha, CEP 31270-901 Belo Horizonte, Minas Gerais, Brazil \\ c Laboratório de Pesquisas Clínicas, Ciências Farmacêuticas, Escola de Farmácia, Universidade Federal de Ouro Preto, Campus \\ Universitário, CEP 35400-000 Ouro Preto, Minas Gerais, Brazil \\ d Laboratório de Imunopatologia, Núcleo de Pesquisas em Ciências Biológicas, Instituto de Ciências Exatas e Biológicas, Universidade \\ Federal de Ouro Preto, Campus Universitário, CEP 35400-000 Ouro Preto, Minas Gerais, Brazil \\ e Laboratório de Parasitologia Básica, Departamento de Ciências Biológicas, Universidade Federal de Alfenas, 37130-000 Alfenas, Minas \\ Gerais, Brazil \\ ${ }_{\mathrm{f}}^{\mathrm{f}}$ Instituto Nacional de Ciência e Tecnologia em Doenças Tropicais, Salvador, Bahia, Brazil
}

\section{A R T I C L E I N F O}

Article history:

Received 5 March 2013

Received in revised form 9 July 2013

Accepted 19 July 2013

\section{Keywords:}

Risk factors

Incidence

Canine visceral leishmaniasis

Leishmania infantum

Cohort study

PCR-RFLP

\begin{abstract}
A B S T R A C T
Zoonotic visceral leishmaniasis in Brazil is caused by Leishmania infantum parasites and is transmitted by sand flies of the Phlebotominae family. Dogs are the main urban reservoirs and represent the major source of contagion for the vectors. Studies have shown that most infected dogs are polymerase chain reaction-positive months before seroconversion. Herein, we describe a cohort study designed to identify the incidence of and risk factors for $L$. infantum infection as detected by polymerase chain reaction-restriction fragment length polymorphism. To determine the risk factors for infection, we conducted a baseline canine survey $(n=1443)$ from which dogs were selected for the cohort study $(n=282)$ involving three evaluations over the course of a 26-month follow-up period. Serology, molecular tests, and a structured questionnaire were used. The risk factors for infection were identified by means of the Cox regression model. The overall infection incidence was 5.8 per 100 dog-months (95\% confidence interval 5.1-6.5). Increased risk of infection was associated with the presence of previous cases of canine visceral leishmaniasis in the domiciles (hazard ratio [HR] 1.4; 95\% confidence interval $[\mathrm{CI}] 1.1-1.8$ ) and unplastered house walls (HR 3.6; 95\% CI 1.6-8.1). These risk factors suggest that insecticide spraying in cracks and crevices in unplastered walls can reduce biting rates within and around homes. Furthermore, our results demonstrate that the Visceral Leishmaniasis Control and Surveillance Program should adopt environmental management measures in homes with previous cases of canine visceral leishmaniasis, because these homes are more likely to maintain the transmission cycle.
\end{abstract}

(C) 2013 Elsevier B.V. All rights reserved.

\footnotetext{
* Corresponding author at: Laboratório de Epidemiologia das Doenças Infecciosas e Parasitárias, Parasitologia, Instituto de Ciências Biológicas, Campus Pampulha, Universidade Federal de Minas Gerais, Avenida Antônio Carlos, 6627, CEP 31270-901 Belo Horizonte, Minas Gerais, Brazil.

Tel.: +55 2131 34092839; fax: +55 213134092970 .

E-mail address: wendelcoura@gmail.com (W. Coura-Vital).
} 


\section{Introduction}

Visceral leishmaniasis is caused by Leishmania donovani or L. infantum, protozoan parasites that are transmitted to human and animal hosts by the bite of phlebotomine sand flies (Chappuis et al., 2007). Depending on whether or not a reservoir host is present, there are two basic types of epidemiological cycles: zoonotic, generally caused by $L$. infantum, and anthroponotic, generally caused by L. donovani (Palatnik-de-Sousa et al., 2001). Dogs are the main urban reservoirs of $L$. infantum and represent the major source of contagion for the vectors by virtue of the high prevalence of infection and intense cutaneous parasitism (Molina et al., 1994; Giunchetti et al., 2006).

Canine visceral leishmaniasis (CVL) is present in approximately 50 countries, mainly in South America and the Mediterranean region (Solano-Gallego et al., 2009; DantasTorres et al., 2012). Epidemiological studies in endemic areas have demonstrated that the prevalence of infection as determined by molecular techniques (50-80\%) is higher than the seroprevalence (10-30\%) (Solano-Gallego et al., 2009; Wang et al., 2011). A cohort study conducted by Oliva et al. (2006) showed that most of the study animals were polymerase chain reaction (PCR)-positive months before seroconversion. The CVL infection rate depends on several factors including the length of the transmission season, the vector density, the susceptibility of the dog population, dog behavior, the degree of exposure to vectors, and dog owners' attitudes toward prevention (Baneth et al., 2008; Dantas-Torres et al., 2012). Preventing the expansion and urbanization of zoonotic visceral leishmaniasis (ZVL) requires that the risk factors associated with human and canine infection be identified. Some cross-sectional serological surveys have suggested that canine susceptibility to infection is associated with dog size, fur length, age, and housing conditions (FrancaSilva et al., 2003; Almeida et al., 2009; Galvez et al., 2010; Cortes et al., 2012). During a previously reported cross-sectional study carried out in an urban area of Brazil (Belo Horizonte, southeastern Brazil), we evaluated the prevalence of and risk factors associated with L. infantum infection in dogs, as identified by means of a molecular test (polymerase chain reaction-restriction fragment length polymorphism, PCR-RFLP) (Coura-Vital et al., 2011b). Some studies have evaluated the risk factors associated with $L$. infantum infection in dogs, however few have used a cohort studies (Belo et al., 2013), which is the most appropriate observational design to establish causal inference. Recently in cohort study we demonstrated that dogs with PCR positive for $L$. infantum showed approximately twice the risk of seroconversion as those that were PCR negative (Coura-Vital et al., 2013). Herein, we report the results of a cohort study designed to identify the incidence of and risk factors for L. infantum infection as identified by PCR-RFLP; we evaluated the domiciliary and peridomiciliary environments, the socioeconomic status of the owners, the type of care provided for the animals, and specific animal behaviors.

\section{Methods}

\subsection{Baseline survey (cross-sectional study)}

The rationale for and organization of the study and the data collection methods have been described elsewhere (Coura-Vital et al., 2011b). Briefly, a cross-sectional study was carried out in the northwest sanitary district $\left(36,874 \mathrm{~km}^{2}\right)$ of Belo Horizonte in 2008 . According to a census conducted by the Brazilian Institute of Geography and Statistics, the human population of this area was 331,362 in 2000. The canine population comprised 20,883 animals in 2008, according to the Zoonosis Control Management. At the time of this study, the seroprevalence in Belo Horizonte $(7.6 \%)$ was similar to that in the northwest sanitary district (7.8\%) ( $\mathrm{PBH}, 2007)$. With an expected CVL positivity in the study area between $5 \%$ and $10 \%$, a confidence interval (CI) of $95 \%$, and an estimated precision of $1.5 \%$, the required sample size for the study was approximately 1500 animals. A total of 918 households were visited, and 1443 dogs were included in the baseline survey (Coura-Vital et al., 2011b).

\subsection{Follow-up cohort study}

We then conducted a follow-up cohort study consisting of three evaluations. Evaluation I was conducted 10 months after the baseline survey (April 2009), and a total of 282 seronegative/PCR-negative dogs were enrolled. This number of dogs was similar to the number of PCRpositive dogs in the cross-sectional study. Households with seronegative/PCR-negative dogs were selected by proximity to the seronegative/PCR-positive dogs. The dogs were selected from 222 owners, all of whom were interviewed; all dogs were clinically examined, and blood was collected by venipuncture. Evaluation II was conducted 16 months after the baseline survey (October 2009), and 225 dogs were tested. Evaluation III was carried out 26 months after the baseline survey (August 2010), and 178 dogs were tested. All the dogs included in evaluations II and III were subjected to the same procedures used in evaluation I.

To evaluate loss trends during the cohort study, we compared the sex, size, and fur length of the included dogs with the same variables for the unincluded dogs in each evaluation.

\subsection{Data and sample collection}

A trained research team interviewed the owners of the study animals using a previously tested structured questionnaire that sought information regarding (i) the owner's knowledge about the human disease (i.e., form of transmission and clinical signs of human visceral leishmaniasis); (ii) the owner's knowledge about the vector (characteristics and presence in the domicile and peridomicile); (iii) the owner's knowledge about the reservoir host (epidemiological importance of the host, clinical signs of CVL, and dog care); (iv) the owner's socioeconomic characteristics (per capita/family income and schooling); (v) the characteristics of the domicile, annexes, and surroundings (i.e., structure of roof, floor, and walls; number of rooms, including 
bedrooms; number of residents; and presence of trees [particularly banana trees], rubble, manure, exposed garbage, dry leaves, and a vegetable garden); (vi) the method of garbage disposal (collected, burned, or buried); and (vii) the presence of other domestic animals (birds, cats, and cattle). The following information was collected for each dog: age, sex, size, fur length, breed, behavior (habits related to the place where the dog slept and spent most of its time, e.g., street, residence, or backyard), dog care, clinical examinations, past history of vaccination, and serological exams previous to leishmaniasis.

A sample of peripheral blood $(5 \mathrm{~mL})$ was collected by puncture of the brachiocephalic vein, and an aliquot was transferred to a glass vial containing sufficient anticoagulant (ethylenediaminetetraacetic acid) to achieve a final concentration of $1 \mathrm{mg} / \mathrm{mL}$. The blood sample was centrifuged (1500-1800 $\times \mathrm{g} ; 20 \mathrm{~min})$, and the buffy coat fraction containing the leukocytes was removed, resuspended in an equal volume of $10 \mathrm{mM}$ Tris- $\mathrm{HCl}$ buffer (supplemented with $1 \mathrm{mM}$ ethylenediaminetetraacetic acid), and stored at $-70^{\circ} \mathrm{C}$ until PCR-RFLP. The remaining portion of the blood sample was transferred to two separate filter papers for subsequent enzyme-linked immunosorbent assay (ELISA) analysis.

\subsection{ELISA}

Each of the eluates from the blood dried on the filter papers was tested by means of two ELISA protocols. The first protocol used a Canine Leishmaniasis EIE Kit (Bio-Manguinhos/Fiocruz, Rio de Janeiro, Brazil), which employs a soluble antigen from promastigote forms of L. major-like parasites (ELISA-L. major-like). This serology was performed in the Laboratory of Zoonosis of the Belo Horizonte Health Department according to the manufacturer's instructions. The second ELISA protocol was performed in parallel with soluble $L$. infantum (MHOM/BR/1070/BH46) antigen and was carried out in the Laboratory of Immunopathology of the Federal University of Ouro Preto as described by Coura-Vital et al. (2011b).

\subsection{PCR-RFLP}

DNA was extracted from the buffy coat fractions by means of a Wizard Genomic DNA Purification Kit (Promega Corporation, Madison, WI, USA) according to the manufacturer's instructions. The primers used to amplify the conserved region of the Leishmania kDNA minicircle were as follows: forward, 5'-GGG (G/T)AG GGG CGT TCT (G/C)CG AA- $3^{\prime}$; reverse, $5^{\prime}-(\mathrm{G} / \mathrm{C})(\mathrm{G} / \mathrm{C})(\mathrm{G} / \mathrm{C})(\mathrm{A} / \mathrm{T}) \mathrm{CT}$ AT(A/T) TTA CAC CAA CCC C-3' (Passos et al., 1999). A single PCR product of $120 \mathrm{bp}$ was generated (Degrave et al., 1994). PCR was performed as described by Coura-Vital et al. (2011b).

PCR amplicons $(5 \mu \mathrm{L})$ were digested for $3 \mathrm{~h}$ at $37^{\circ} \mathrm{C}$ in $1 \mathrm{U}$ of HaeIII (Invitrogen, Carlsbad, CA, USA) in $1 \times$ buffer (10 mM Tris- $\mathrm{HCl}, 10 \mathrm{mM} \mathrm{MgCl} 2$ [pH 7.5]) and enough Milli-Q water to bring the final volume to $15.0 \mu \mathrm{L} /$ well (MicroAmp Fast Optical 96-Well Reaction Plate, Applied Biosystems, Foster City, CA, USA) (Volpini et al., 2004). Restriction fragments, together with a 25-bp DNA ladder (Invitrogen, São Paulo, Brazil), underwent electrophoresis in $10 \%$ polyacrylamide gels at $40 \mathrm{~mA}$ in $89 \mathrm{mM}$ Tris base (pH 8.0), $89 \mathrm{mM}$ boric acid, and $2 \mathrm{mM}$ ethylenediaminetetraacetic acid. Bands were detected by silver staining, and the patterns were compared with those obtained with DNA from $L$. (L.) amazonensis (strain MHOM/BR/1973/M2269), $L$. (Viannia) braziliensis (strain MHOM/BR/1975/M2903), and L. (L.) infantum (strain MHOM/BR/1972/BH46) from the DNA reference library at the Laboratory of Immunopathology of the Federal University of Ouro Preto.

\subsection{Statistical analysis}

Databases were generated with EpiData software (version 3.2, EpiData Association, Odense, Denmark) by double entry of the results and were subsequently corrected, compared, and analyzed with Stata software (version 11.0, StataCorp, College Station, TX, USA). The incidence of $L$. infantum infection as indicated by PCR-RFLP was estimated per 100 dog-months. The Cox proportional hazard model was used to evaluate the risk factors associated with infection by L. infantum. Variables that were statistically significant but exhibited colinearity were excluded from the multivariate analysis, and categorical variables were transformed into dummy variables. The univariate analysis was performed by means of Kaplan-Meir survival analysis following by a log-rank test to examine the associations between each variable and time to infection. A multivariable adjusted model was fitted with the variables that were statistically significant at $p<0.25$ in univariate analyses. A step-by-step backward selection procedure was used to select the variables and to produce the final multivariate regression model. Only adjusted variables showing a significant association $(p<0.05)$ with the occurrence of infection by $L$. infantum remained in the final model. The strength of association was determined by a hazard ratio and a $95 \% \mathrm{CI}$. The Schoenfeld test was performed to test the proportional hazards assumption.

\subsection{Ethics}

The study was approved by the Ethics Committee in Animal Experimentation of the Federal University of Ouro Preto (protocol no. 083/2007), of the Federal University of Minas Gerais (protocol no. 020/2007), and of the Belo Horizonte City Council (protocol no. 001/2008). All procedures in this study were conducted according to the guidelines set out by the Brazilian Animal Experimental College (federal law number 11794). Owners of dogs participating in the project were informed of the research objectives and were required to sign an informed consent form before sample and data collection.

\section{Results}

\subsection{Characteristics of the dogs and housing conditions}

The gender, size, and fur length of the dogs in the cohort study (50.0\% female, $50.0 \%$ medium sized, and $57.1 \%$ short fur) were similar to those in the baseline survey. The mean age was 54.3 months (standard deviation [SD] 41.7), the median (interquartile range [IQR]) was 48 months (IQR 24; 
Table 1

Characteristics of the dogs in the cohort study $(n=282)$, Brazil 2010 .

\begin{tabular}{|c|c|c|}
\hline Variable & No. & $\%$ \\
\hline \multicolumn{3}{|l|}{ Gender } \\
\hline Female & 141 & 50.0 \\
\hline Male & 141 & 50.0 \\
\hline \multicolumn{3}{|l|}{ Size } \\
\hline Small & 81 & 28.7 \\
\hline Medium & 141 & 50.0 \\
\hline Big & 60 & 21.3 \\
\hline \multicolumn{3}{|l|}{ Fur length } \\
\hline Long & 161 & 57.1 \\
\hline Short & 121 & 42.9 \\
\hline \multicolumn{3}{|l|}{ Age } \\
\hline$\leq 24$ months & 97 & 34.4 \\
\hline$>24$ and $\leq 84$ months & 123 & 43.6 \\
\hline$>84$ months & 62 & 22.0 \\
\hline \multicolumn{3}{|l|}{ Origin of the animal } \\
\hline District of residence & 158 & 56.0 \\
\hline Other district & 124 & 44.0 \\
\hline \multicolumn{3}{|c|}{ Dog stayed predominantly in the backyard } \\
\hline No & 35 & 12.4 \\
\hline Yes & 247 & 87.6 \\
\hline \multicolumn{3}{|l|}{ Sleeping place } \\
\hline Inside the house & 46 & 16.3 \\
\hline In the backyard & 236 & 83.7 \\
\hline \multicolumn{3}{|l|}{ Had access to the street } \\
\hline No & 253 & 89.7 \\
\hline Yes & 29 & 10.3 \\
\hline \multicolumn{3}{|l|}{ Veterinary checkups } \\
\hline Yes & 141 & 50.0 \\
\hline No & 141 & 50.0 \\
\hline
\end{tabular}

72). One hundred twenty-three dogs (43.6\%) were between 24 and 84 months. Most of the animals lived and slept in the backyard ( 87.6 and $83.7 \%$, respectively) rather than inside the residence. Only 29 (10.3\%) of the dogs had easy access to the street. Half of the dogs were regularly checked by a veterinarian (Table 1 ).

A total of 222 households were selected. They had a mean of 1.3 (SD 0.8) dogs per household (1-7 dogs/house) and median of 1 (IQR $1 ; 1)$. Most of the dwellings (142; $63.9 \%)$ were detached houses, 216 (97.3\%) had plastered walls, $183(82.4 \%)$ had a garden, and $100 \%$ were served by a sewage main. Garbage was collected at least 3 times per week from 202 (91.8\%) residences. The mean numbers of rooms and bedrooms per house were 7.2 (SD 2.8) and 2.6 (SD 0.9), respectively. Each dwelling had an average of 4.1 (SD 1.8) residents (data not shown).

\subsection{Losses to follow-up}

Prior to evaluations II and III, 57 and 47 dogs were lost to follow-up respectively. The reasons for losses to followup were euthanasia (seroconversion), death, change of address, household closed, refusal, and dog escape. The closed houses were visited 3 times before the dogs were considered lost to follow-up. Comparisons of the characteristics of the evaluated dogs and those lost to follow-up in each evaluation phase did not reveal any differences.

\subsection{Incidence and risk factors for L. infantum infection}

Among 282 seronegative and PCR-RFLP-negative dogs, 234 showed failure events as indicated by PCR-RFLP during
Table 2

Failure events (PCR-RFLP), dog-months of follow-up, and incidence rates with 95\% CIs, Brazil 2010.

\begin{tabular}{llcc}
\hline Follow-up & \multicolumn{3}{l}{ PCR-RFLP } \\
\cline { 2 - 4 } & $\begin{array}{l}\text { No. of failure } \\
\text { events }\end{array}$ & Dog-months & $\begin{array}{l}\text { Incidence rate } \\
(95 \% \mathrm{CI})^{\mathrm{a}}\end{array}$ \\
\hline Evaluation I $^{\mathrm{b}}$ & 109 & 3557 & $3.1(2.5-3.7)$ \\
Evaluation II $^{\mathrm{c}}$ & 112 & 436 & $25.7(21.3-30.9)$ \\
Evaluation III $^{\mathrm{d}}$ & 13 & 67 & $19.4(11.1-33.1)$ \\
Total & 234 & 4061 & $5.8(5.1-6.5)$ \\
\hline
\end{tabular}

a Per 100 dog-months.

b 10 months after the baseline survey.

c 16 months after the baseline survey.

d 26 months after the baseline survey.

follow-up (26 months), and the overall incidence for 4061 dog-months was 5.8 per 100 dog-months (95\% CI 5.1-6.5). The first evaluation showed 109 events (PCR-RFLP), and an incidence of 3.1 per 100 dog-months (95\% CI 2.5-3.7). Evaluations II and II showed 112 and 13 events, with incidences of 25.7 (95\% CI 21.3-30.9) and 19.4 per 100 dog-months (95\% CI 11.1-33.1), respectively (Table 2). The results of the preliminary selection of the variables from the univariate analysis $(p<0.25)$ as well as the hazard ratios (HR), number of failure events, and incidences per 100 dog-months are shown in Table 3 . The variables selected to build the final model ( $p<0.15$ ) were dog fur length (long/short), previous case of CVL in the household (yes/no), unplastered house walls (yes/no), regular garbage collection $(<3 \times$ per week/ $\geq 3 \times$ per week), access to the street (yes/no), and previous serological examination for CVL (yes/no). Infection with L. infantum (PCR-RFLP) was associated with a previous case of CVL in the household (HR 1.4; 95\% CI 1.1-1.8) and unplastered house walls (HR 3.6; 95\% CI 1.6-8.1) (Table 4).

\section{Discussion}

The present investigation showed that the condition of the domicile and the presence of a previous case of CVL in the household were associated with early $L$. infantum infection in dogs. Thus, it was possible to determine the role of household structures as a predictor of canine infection occurrence in urban areas. These results are relevant because they allow a better understanding of how household structure may affect the urbanization of ZVL and thus what control measures might be adopted to more effectively control the spread of the disease.

Studies have shown that molecular methods not only lead to more accurate Leishmania detection (SolanoGallego et al., 2009) but also reveal the presence of protozoan DNA very early, before seroconversion and clinical manifestations (Quinnell et al., 2001; Oliva et al., 2006; Coura-Vital et al., 2011a). In experimentally infected dogs, seroconversion can take from 1 to 6 months (Moreno and Alvar, 2002), whereas in naturally infected animals, the median time to seroconversion is 10.5 months (range, 4-22 months) (Oliva et al., 2006). These facts emphasize the importance of early detection of infection by molecular methods. For CVL diagnosis, PCR can be performed on samples from a broad range of tissues with various degrees of sensitivity (Manna et al., 2004; Di Muccio et al., 2012). 
Table 3

Univariate analysis using Kaplan-Meier survival analysis and the Cox regression model, to determine risk factors for Leishmania infantum infection, Brazil 2010.

\begin{tabular}{|c|c|c|c|c|c|c|c|}
\hline Variable & No. of failure events & No. of measured & Time at risk & Incid./100 dog-month & HR & $95 \% \mathrm{CI}$ & $p$ \\
\hline \multicolumn{8}{|l|}{ Vector/reservoir } \\
\hline \multicolumn{8}{|l|}{ Seen the vector } \\
\hline No & 220 & 267 & 3859 & 5.7 & 1 & & \\
\hline Yes & 14 & 15 & 210 & 6.7 & 1.47 & $0.85-2.53$ & 0.17 \\
\hline \multicolumn{8}{|c|}{ Previous case of CVL in the household } \\
\hline No & 162 & 198 & 2918 & 5.5 & 1 & & \\
\hline Yes & 72 & 84 & 1151 & 6.3 & 1.35 & $1.02-1.78$ & 0.04 \\
\hline \multicolumn{8}{|c|}{ Housing conditions } \\
\hline \multicolumn{8}{|c|}{ Unplastered house walls } \\
\hline No & 228 & 276 & 4000 & 5.7 & 1 & & \\
\hline Yes & 6 & 6 & 70 & 8.6 & 3.37 & $1.49-7.63$ & 0.00 \\
\hline \multicolumn{8}{|c|}{ Regular garbage collection } \\
\hline$\geq 3 \times /$ week & 216 & 257 & 3682 & 5.9 & 1 & & \\
\hline$<3 \times /$ week & 15 & 22 & 343 & 4.4 & 0.63 & $0.37-1.05$ & 0.08 \\
\hline \multicolumn{8}{|c|}{ Trees in backyard } \\
\hline No & 122 & 152 & 2236 & 5.4 & 1 & & \\
\hline Yes & 112 & 130 & 1832 & 6.1 & 1.17 & $0.91-1.52$ & 0.22 \\
\hline \multicolumn{8}{|c|}{ Characteristics of dogs } \\
\hline \multicolumn{8}{|c|}{ Fur length } \\
\hline Long & 95 & 121 & 1747 & 5.4 & 1 & & \\
\hline Short & 139 & 161 & 2322 & 6.0 & 1.21 & $0.93-1.57$ & 0.16 \\
\hline \multicolumn{8}{|c|}{ Dog stayed predominantly in the backyard } \\
\hline No & 27 & 35 & 543 & 5.0 & 1 & & \\
\hline Yes & 207 & 247 & 3526 & 5.9 & 1.40 & $0.93-2.08$ & 0.10 \\
\hline \multicolumn{8}{|c|}{ Had access to the street } \\
\hline No & 207 & 253 & 3681 & 5.6 & 1 & & \\
\hline Yes & 27 & 29 & 387 & 7.0 & 1.38 & $0.92-2.05$ & 0.12 \\
\hline \multicolumn{8}{|c|}{ Previous serological examination for CVL } \\
\hline Yes & 179 & 217 & 3161 & 5.7 & 1 & & \\
\hline No & 48 & 55 & 755 & 6.4 & 1.38 & $1.00-1.91$ & 0.05 \\
\hline
\end{tabular}

HR, hazard ratio; CI, confidence interval; CVL, canine visceral leishmaniasis.

Although the peripheral blood is not the most sensitive sample, it is the most useful for mass surveys because sample collection is less invasive and the use of peripheral blood allows serology to be performed concurrently (Lachaud et al., 2002a,b), allowing the detection of most of the infected dogs.

The incidence of $L$. infantum infection as detected by PCR-RFLP was high; at the end of 26 months of follow-up, almost all the dogs had been infected. These results indicate that Belo Horizonte is an area of active CVL transmission. The incidence of CVL is an important epidemiologic parameter to consider in prioritizing target control areas. Detection of DNA by PCR effectively assists in CVL diagnosis, mostly for dogs with uncertain serology status or for dogs that have not seroconverted (Martinez et al., 2011).

CVL is currently spreading to non-endemic areas in Europe (Dereure et al., 2009) and recently emerged in North America (Petersen, 2009). Furthermore, an increase in the prevalence of ZVL has been observed in urban areas, which may be attributed to high population density, increased migration, environmental changes, inadequate living conditions, and the presence of vector and reservoir in the domestic environment (Desjeux, 2004; Oliveira et al., 2008). Because dogs are the main reservoirs for L. infantum in humans, we investigated the risk factors associated with L. infantum infection in dogs. Identification of factors associated with CVL might be useful for identifying areas of higher ZVL risk, because infection in dogs generally precedes the occurrence of human cases (Nunes et al., 2010).

We observed that canine infection by $L$. infantum was associated with the presence of unplastered house walls. Sand flies are crepuscular and nocturnal, and during the day, they rest in comparatively cool, humid areas, including houses, latrines, basements, and wall fissures (KillickKendrick, 1999). Sand flies can hide in cracks in unplastered walls, which facilitates contact between the vector and dogs. The occurrence of Lutzomyia longipalpis in cracks and crevices of house walls has been observed in endemic areas of northeastern Brazil (Deane and Deane, 1962). In a casecontrol study conducted in Nepal, cracks in house walls

Table 4

Risk factors for Leishmania infantum infection in dogs, Brazil 2010.

\begin{tabular}{lcc}
\hline Variable & Crude hazard ratio $(95 \% \mathrm{CI})$ & Adjusted hazard ratio $(95 \% \mathrm{CI})$ \\
\hline $\begin{array}{l}\text { Previous case of CVL in the household } \\
\text { Yes versus no }\end{array}$ & $1.3(1.0-1.8)$ & $1.4(1.1-1.8)$ \\
$\begin{array}{l}\text { Unplastered house walls } \\
\text { No versus yes }\end{array}$ & $3.4(1.5-7.6)$ & $3.6(1.6-8.1)$ \\
\hline
\end{tabular}

$\mathrm{CI}$, confidence interval. 
were found to be associated with elevated human visceral leishmaniasis risk (Bern et al., 2000). A case-control study by Costa et al. (2005) in Teresina, Brazil, revealed no association between risk of infection by L. infantum and unplastered walls, ceiling, floor, and water supply; however, the lack of sewerage or regular collection of garbage was associated with increased ZVL incidence. These findings demonstrate that basic public services are important in controlling the spread of the disease (Costa et al., 2005). In the current study, almost all households evaluated had sewerage and garbage collection, making it impossible to detect the influence of these factors on canine infection.

Housing conditions generally reflect socioeconomic status. The cross-sectional study on which this cohort study was based demonstrated that one factor associated with L. infantum infection (as indicated by PCR-RFLP) was the socioeconomic status of the owner (Coura-Vital et al., 2011b). Indeed, Oliveira et al. (2006) demonstrated an association between ZVL and family income in the Belo Horizonte metropolitan area. Our data are also consistent with literature confirming that ZVL is more incident in areas of precarious socioeconomic status (Werneck et al., 2007).

In Brazil, the main strategies used by the Visceral Leishmaniasis Control and Surveillance Program have been vector control and culling of infected dogs. However, these measures have been found to be insufficient to contain disease dissemination (Harhay et al., 2011). In this study, we observed that dogs residing in households with previous case of CVL showed a higher risk of infection than dogs residing in households with no previous cases. Similar results were observed in a study conducted in Teresina, Brazil, where in households with a history of dog removal by the program, the odds of having at least one infected dog were 5 times the odds in dwellings with no history of dog removal (da Silva et al., 2012). This result may have been due to an environment favorable to the development of the vector in the domiciles, causing the occurrence of new cases. According to da Silva et al. (2012), simply removing a seropositive dog from a household, without taking environmental management measures, does not prevent future infections in other animals in that household.

One limitation of cohort studies is loss to follow-up; however, in the current study, the dogs lost to follow-up did not differ substantially from those that remained, as indicated by comparison of several characteristics. Therefore, the effect of loss to follow-up was minimized. The present study was designed not to evaluate a representative sample of Belo Horizonte but to assess the incidence of and identify risk factors for $L$. infantum infection. However, the northwest sanitary district is representative of the city in terms of buildings, commerce, residences, and green areas.

\section{Conclusion}

We identified domicile characteristics that were associated with an increased risk of canine infection by $L$. infantum. The identification of these risk factors indicates the necessity for insecticide spraying in cracks and crevices in the walls of houses to reduce biting rates within and around houses. Furthermore, our results demonstrate that the Visceral Leishmaniasis Control and Surveillance Program should adopt environmental management measures in homes with previous cases of CVL because these households are more likely to maintain the transmission cycle.

\section{Acknowledgements}

This study was supported by the following grants: PNPD/Institutional/2011, DECIT/MS/CNPq/BR/grant: 57 6062/2008-1; FAPEMIG/BR/grant: CBB-APQ-3073-4.01/07, CNPq/BR/grant: 472554/2007-7; PPSUS/MS/ CNPq/ FAPEMIG/ SES-MG/grant CBB-APQ-00356-10; FAPEMIG/ PPM and Federal University of Ouro Preto. The funders had no role in study design, data collection or analysis, the decision to publish, or the preparation of the manuscript. ABR and MC are grateful for CNPq fellowships, and WCV is grateful to the PNPD/CAPES fellowships. We also thank the staff of the Secretaria Municipal de Saúde de Belo Horizonte, Minas Gerais, for cooperation, logistical support, and special dedication to this work.

\section{References}

Almeida, A.B., Faria, R.P., Pimentel, M.F., Dahroug, M.A., Turbino, N.C., Sousa, V.R., 2009. Seroepidemiological survey of canine leishmaniasis in endemic areas of Cuiaba, State of Mato Grosso. Rev. Soc. Bras. Med. Trop. 42, 156-159.

Baneth, G., Koutinas, A.F., Solano-Gallego, L., Bourdeau, P., Ferrer, L., 2008. Canine leishmaniosis - new concepts and insights on an expanding zoonosis: part one. Trends Parasitol. 24, 324-330.

Belo, V.S., Struchiner, C.J., Werneck, G.L., Barbosa, D.S., de Oliveira, R.B. Neto, R.G., da Silva, E.S., 2013. A systematic review and meta-analysis of the factors associated with Leishmania infantum infection in dogs in Brazil. Vet. Parasitol. 195, 1-13.

Bern, C., Joshi, A.B., Jha, S.N., Das, M.L., Hightower, A., Thakur, G.D., Bista, M.B., 2000. Factors associated with visceral leishmaniasis in Nepal: bed-net use is strongly protective. Am. J. Trop. Med. Hyg. 63, 184-188.

Chappuis, F., Sundar, S., Hailu, A., Ghalib, H., Rijal, S., Peeling, R.W., Alvar, J., Boelaert, M., 2007. Visceral leishmaniasis: what are the needs for diagnosis, treatment and control? Nat. Rev. Microbiol. 5, 873-882.

Cortes, S., Vaz, Y., Neves, R., Maia, C., Cardoso, L., Campino, L., 2012. Risk factors for canine leishmaniasis in an endemic Mediterranean region. Vet. Parasitol. 189, 189-196.

Costa, C.H., Werneck, G.L., Rodrigues Jr., L., Santos, M.V., Araujo, I.B., Moura, L.S., Moreira, S., Gomes, R.B., Lima, S.S., 2005. Household structure and urban services: neglected targets in the control of visceral leishmaniasis. Ann. Trop. Med. Parasitol. 99, 229-236.

Coura-Vital, W., Marques, M.J., Giunchetti, R.C., Teixeira-Carvalho, A., Moreira, N.D., Vitoriano-Souza, J., Vieira, P.M., Carneiro, C.M., CorreaOliveira, R., Martins-Filho, O.A., Carneiro, M., Reis, A.B., 2011 a. Humoral and cellular immune responses in dogs with inapparent natural Leishmania infantum infection. Vet. J. 190, e43-e47.

Coura-Vital, W., Marques, M.J., Veloso, V.M., Roatt, B.M., Aguiar-Soares, R.D., Reis, L.E., Braga, S.L., Morais, M.H., Reis, A.B., Carneiro, M., 2011b. Prevalence and factors associated with Leishmania infantum infection of dogs from an urban area of Brazil as identified by molecular methods. PLoS Negl. Trop. Dis. 5, e1291.

Coura-Vital, W., Reis, A.B., Fausto, M.A., Leal, G.G.A., Marques, M.J., Veloso, V.M., Carneiro, M., 2013. Risk factors to seroconversion by Leishmania infantum in a cohort of dogs from an endemic area of Brazil. PLoS ONE, http://dx.doi.org/10.1371/journal.pone.0071833 (in press).

da Silva, J.P., Werneck, G.L., Macedo, E.C., de Carvalho, H., Cruz Mdo, S., 2012. Factors associated with Leishmania chagasi infection in domestic dogs from Teresina, State of Piaui, Brazil. Rev. Soc. Bras. Med. Trop. 45, 480-484.

Dantas-Torres, F., Solano-Gallego, L., Baneth, G., Ribeiro, V.M., de PaivaCavalcanti, M., Otranto, D., 2012. Canine leishmaniosis in the old and new worlds: unveiled similarities and differences. Trends Parasitol. 28, 531-538.

Deane, L.M., Deane, M.P., 1962. Visceral leishmaniasis in Brazil: geographical distribution and transmission. Rev. Inst. Med. Trop. São Paulo 4 $198-212$ 
Degrave, W., Fernandes, O., Campbell, D., Bozza, M., Lopes, U., 1994. Use of molecular probes and PCR for detection and typing of Leishmania a mini-review. Mem. Inst. Oswaldo Cruz 89, 463-469.

Dereure, J., Vanwambeke, S.O., Male, P., Martinez, S., Pratlong, F., Balard, Y., Dedet, J.P., 2009. The potential effects of global warming on changes in canine leishmaniasis in a focus outside the classical area of the disease in southern France. Vector Borne Zoonotic Dis. 9, 687-694.

Desjeux, P., 2004. Leishmaniasis: current situation and new perspectives. Comp. Immunol. Microbiol. Infect. Dis. 27, 305-318.

Di Muccio, T., Veronesi, F., Antognoni, M.T., Onofri, A., Piergili Fioretti, D., Gramiccia, M., 2012. Diagnostic value of conjunctival swab sampling associated with nested PCR for different categories of dogs naturally exposed to Leishmania infantum infection. J. Clin. Microbiol. 50, 2651-2659.

Franca-Silva, J.C., da Costa, R.T., Siqueira, A.M., Machado-Coelho, G.L., da Costa, C.A., Mayrink, W., Vieira, E.P., Costa, J.S., Genaro, O., Nascimento, E., 2003. Epidemiology of canine visceral leishmaniosis in the endemic area of Montes Claros Municipality, Minas Gerais State, Brazil. Vet. Parasitol. 111, 161-173.

Galvez, R., Miro, G., Descalzo, M.A., Nieto, J., Dado, D., Martin, O., Cubero, E., Molina, R., 2010. Emerging trends in the seroprevalence of canine leishmaniasis in the Madrid region (central Spain). Vet. Parasitol. 169, 327-334.

Giunchetti, R.C., Mayrink, W., Genaro, O., Carneiro, C.M., Correa-Oliveira, R., Martins-Filho, O.A., Marques, M.J., Tafuri, W.L., Reis, A.B., 2006. Relationship between canine visceral leishmaniosis and the Leishmania (Leishmania) chagasi burden in dermal inflammatory foci. J. Comp. Pathol. 135, 100-107.

Harhay, M.O., Olliaro, P.L., Costa, D.L., Costa, C.H., 2011. Urban parasitology: visceral leishmaniasis in Brazil. Trends Parasitol. 27, 403-409.

Killick-Kendrick, R., 1999. The biology and control of phlebotomine sand flies. Clin. Dermatol. 17, 279-289.

Lachaud, L., Chabbert, E., Dubessay, P., Dereure, J., Lamothe, J., Dedet, J.P., Bastien, P., 2002a. Value of two PCR methods for the diagnosis of canine visceral leishmaniasis and the detection of asymptomatic carriers. Parasitology 125, 197-207.

Lachaud, L., Marchergui-Hammami, S., Chabbert, E., Dereure, J., Dedet, J.P., Bastien, P., 2002b. Comparison of six PCR methods using peripheral blood for detection of canine visceral leishmaniasis. J. Clin. Microbiol. 40, 210-215.

Manna, L., Vitale, F., Reale, S., Caracappa, S., Pavone, L.M., Morte, R.D., Cringoli, G., Staiano, N., Gravino, A.E., 2004. Comparison of different tissue sampling for PCR-based diagnosis and follow-up of canine visceral leishmaniosis. Vet. Parasitol. 125, 251-262.

Martinez, V., Quilez, J., Sanchez, A., Roura, X., Francino, O., Altet, L., 2011. Canine leishmaniasis: the key points for qPCR result interpretation. Parasitol. Vectors 4, 57.

Molina, R., Amela, C., Nieto, J., San-Andres, M., Gonzalez, F., Castillo, J.A., Lucientes, J., Alvar, J., 1994. Infectivity of dogs naturally infected with Leishmania infantum to colonized Phlebotomus perniciosus. Trans. R. Soc. Trop. Med. Hyg. 88, 491-493.
Moreno, J., Alvar, J., 2002. Canine leishmaniasis: epidemiological risk and the experimental model. Trends Parasitol. 18, 399-405.

Nunes, C.M., Pires, M.M., da Silva, K.M., Assis, F.D., Goncalves Filho, J., Perri, S.H., 2010. Relationship between dog culling and incidence of human visceral leishmaniasis in an endemic area. Vet. Parasitol. 170,131-133.

Oliva, G., Scalone, A., Foglia Manzillo, V., Gramiccia, M., Pagano, A., Di Muccio, T., Gradoni, L., 2006. Incidence and time course of Leishmania infantum infections examined by parasitological, serologic, and nested-PCR techniques in a cohort of naive dogs exposed to three consecutive transmission seasons. J. Clin. Microbiol. 44, 1318-1322.

Oliveira, C.D., Diez-Roux, A., Cesar, C.C., Proietti, F.A., 2006. A case-control study of microenvironmental risk factors for urban visceral leishmaniasis in a large city in Brazil, 1999-2000. Rev. Panam. Salud Publica 20, 369-376.

Oliveira, C.D., Morais, M.H., Machado-Coelho, G.L., 2008. Visceral leishmaniasis in large Brazilian cities: challenges for control. Cad. Saude Publica 24, 2953-2958.

Palatnik-de-Sousa, C.B., dos Santos, W.R., Franca-Silva, J.C., da Costa, R.T. Reis, A.B., Palatnik, M., Mayrink, W., Genaro, O., 2001. Impact of canine control on the epidemiology of canine and human visceral leishmaniasis in Brazil. Am. J. Trop. Med. Hyg. 65, 510-517.

Passos, V.M., Fernandes, O., Lacerda, P.A., Volpini, A.C., Gontijo, C.M., Degrave, W., Romanha, A.J., 1999. Leishmania (Viannia) braziliensis is the predominant species infecting patients with American cutaneous leishmaniasis in the State of Minas Gerais, Southeast Brazil. Acta Trop. 72, 251-258

PBH, 2007. Informação sobre a leishmaniose, 2005 a 2007, http:// portalpbh.pbh.gov.br/pbh/ecp/comunidade.do?evento=portlet\&pId $\mathrm{Plc}=\mathrm{ecp}$ TaxonomiaMenuPortal\&app=saude\&tax=12768\&lang=pt BR\&pg $=5571 \& \operatorname{taxp}=0 \&$ (accessed 20.08.07).

Petersen, C.A., 2009. Leishmaniasis, an emerging disease found in companion animals in the United States. Top. Companion Anim. Med. 24, $182-188$.

Quinnell, R.J., Courtenay, O., Davidson, S., Garcez, L., Lambson, B., Ramos, P., Shaw, J.J., Shaw, M.A., Dye, C., 2001. Detection of Leishmania infantum by PCR, serology and cellular immune response in a cohort study of Brazilian dogs. Parasitology 122, 253-261.

Solano-Gallego, L., Koutinas, A., Miro, G., Cardoso, L., Pennisi, M.G., Ferrer, L., Bourdeau, P., Oliva, G., Baneth, G., 2009. Directions for the diagnosis, clinical staging, treatment and prevention of canine leishmaniosis. Vet. Parasitol. 165, 1-18.

Volpini, A.C., Passos, V.M., Oliveira, G.C., Romanha, A.J., 2004. PCR-RFLP to identify Leishmania (Viannia) braziliensis and L. (Leishmania) amazonensis causing American cutaneous leishmaniasis. Acta Trop. 90, 31-37.

Wang, J.Y., Ha, Y., Gao, C.H., Wang, Y., Yang, Y.T., Chen, H.T., 2011. The prevalence of canine Leishmania infantum infection in western China detected by PCR and serological tests. Parasitol. Vectors 4, 69.

Werneck, G.L., Costa, C.H., Walker, A.M., David, J.R., Wand, M., Maguire, J.H., 2007. Multilevel modelling of the incidence of visceral leishmaniasis in Teresina, Brazil. Epidemiol. Infect. 135, 195-201. 